Cómo citar este artículo en Chicago: Fonti, Diego. "Aprendizaje y legitimación: sobre fe y conocimiento en También una historia de la filosofía de Jürgen Habermas”. Escritos 28, no. 61 (2020): 148-167. doi: http://dx.doi.org/10.18566/escr.v28n61.a10

Fecha de recepción: 13.10 .2020

Fecha de aceptación: 07.12.2020

\title{
Aprendizaje y legitimación: sobre fe y conocimiento en También una historia de la filosofía de Jürgen Habermas
}

\author{
Learning and legitimacy: On faith and knowledge in This Too \\ a History of Philosophy by Jürgen Habermas
}

Diego Fonti ${ }^{1}$

\begin{abstract}
RESUMEN
El último libro de Habermas, Auch eine Geschichte der Philosophie (2019), se propone reconstruir la genealogía histórica del pensamiento postmetafísico desde una perspectiva notable: la relación de creencia y conocimiento. En este trabajo se exponen dos elementos centrales de esta relación. En primer lugar, se analiza la noción de "proceso de aprendizaje", su modo de operar en la historia del pensamiento y las instituciones, la progresiva "lingüistificación" de los contenidos de fe, las influencias de la interrelación de fe y conocimiento en los procesos de aprendizaje, y el rol de la filosofía en esa historia. Habermas muestra cómo este proceso caracteriza la actividad que dio lugar al pensamiento postmetafísico, excede los límites europeos de su origen, y al mismo tiempo deviene operativo para pensar toda relación en un contexto postsecular. En segundo lugar, se presenta un aspecto particular vinculado con la filosofía práctica: los procesos de legitimación de las normas, instituciones y decisiones. En este sentido, se analiza el paso que la relación de creencia y conocimiento permitió en los problemas de legitimación política, moral y legal. Se mostrarán los principales hitos de los tres campos, su interrelación, y los paradigmas que fundamentaron las posiciones. Se mostrará cómo Habermas encuentra el origen de su posición universalista y procedimental en un recorrido donde la reflexión teológica sobre la experiencia religiosa es imprescindible. A lo largo de este recorrido se muestra el rol que Habermas considera todavía válido para el discurso religioso en el contexto secular. Finalmente se ofrecerá una breve reflexión crítica.
\end{abstract}

Palabras clave: Habermas; Secularismo; Lingüstificación; Proceso de aprendizaje; Legitimación.

1 Doctor en Filosofía por la Albert-Ludwigs Universität Freiburg, Alemania. Profesor Investigador del Conicet y de la Universidad Católica de Córdoba, Argentina. Correo electrónico: diegofonti@gmail.com 


\begin{abstract}
Habermas' last book Auch eine Geschichte der Philosophie (2019). engages a reconstruction of the historical genealogy of postmetaphysical thought from a remarkable perspective: The relationship between faith and knowledge. In this paper I will present two key elements of this relationship. First, I will examine the concept of "learning process", its way of operating in the history of thought and of institutions, the progressive "lingüistification" of the contents of faith, the influences of the relationship of faith and knowledge in learning processes, and the role of philosophy in this history. Second, I will research a particular aspect related to practical philosophy: the process of legitimation of norms, institutions and decisions. In this regards, I wil analyze the advance promoted by the relationship of faith and knowlede in political, moral and legal legitimacy issues. I will show the main milestones of all three fields, their relationship, and the paradigms that based those positions. I will show how Habermas finds the origin of his universalist and procedimentalist position in a path where the theological reflection was indispensable. Along this reconstruction I will also show the contribution that Habermas still considers valid for religious discourse in a secular context. Finally I will offer a brief critical reflection.
\end{abstract}

Keywords: Habermas; Secularism; Linguistification; Learning process; Legitimacy.

$\mathrm{L}$

a aparición en 2019 de Auch eine Geschichte der Philosophie, ha significado un nuevo hito en la dilatada reflexión de Habermas sobre el vínculo entre creencia y conocimiento. Aunque en su obra previa se hallan expresas referencias a la historia de la filosofía y al rol de lo religioso, no había todavía una reconstrucción histórica, mucho menos en clave de la relación entre avances cognitivos y creencias religiosas. Habermas ubica además en esta genealogía del pensamiento postmetafísico su propia comprensión de la racionalidad comunicativa. Sostiene que el avance de la racionalidad filosófica y comunicativa fue impulsado por las tensiones y cooperaciones de los discursos de la fe y del conocimiento.

Las 1700 páginas del libro tienen una intención expresa y numerosos motivos subrogados. La intención expresa es elaborar la genealogía de cómo se dieron, a partir del vínculo entre las creencias de fe y los conocimientos nacidos como respuesta a los diversos planos de interrogantes de la realidad, una serie de procesos de aprendizaje que constituyeron el eje de la historia de la filosofía y condujeron al pensamiento postmetafísico. Entre los motivos subrogados hallamos la reconstrucción del paso de la metafísica a la filosofía del sujeto (conciencia/mente) y finalmente al giro lingüístico; el surgimiento de una autonomía socializada y de una socialización que permite la autonomía y la universalización de la libertad; la explicación del origen de campos específicos en la propia filosofía; los modos de justificación del poder y sus decisiones; etc. Su aproximación histórica permite también trazar continuidades e influencias algunas muy sorprendentes - entre pensadores y épocas históricas.

El objetivo de este trabajo no es hacer una reseña o síntesis, ni mucho menos una elaboración minuciosa de los diversos problemas y autores en esta historia de la filosofía. En cambio, se trata de reconstruir dos aspectos que funcionan como hilo conductor y acompañan la historia de la racionalidad: los modos en que a partir de la interrelación de discursos provenientes del ámbito de la fe y del campo del conocimiento se dieron 1) los procesos de aprendizaje en el avance cognitivo y 2) los modelos de legitimación práctica. Pero antes de abordarlos conviene una exposición de los antecedentes del interés de Habermas sobre el vínculo de fe y saber. ${ }^{2}$

2 Como sucede con otros términos fundamentales, la traducción de Glauben por fe/creer y Wissen por conocimiento/ saber no carece de dificultades. Hay que tener en cuenta que son sustantivaciones de verbos, y que la acción 


\section{Antecedentes}

La herencia marxista de la Escuela de Frankfurt no impidió que lo religioso ingrese de modo productivo y no como mera "premisa de toda crítica". En Habermas, la cuestión del discurso religioso y el rol de las religiones aparece tempranamente, aunque luego adquiere una importancia creciente, con continuidades y variaciones. ${ }^{3}$ Esas variaciones no fueron motivadas sólo por aspectos teóricos sino también por preocupaciones prácticas, como la manipulación genética, los Derechos Humanos y la dignidad humana ${ }^{4}$, y la preocupación ante los fundamentalismos ${ }^{5}$. En paralelo, Habermas estableció un intercambio fluido con teólogos tan diferentes como Metz y Ratzinger, que le permitió ajustar a partir del diálogo efectivo sus propias posiciones respecto del rol y sentido de lo religioso en las sociedades modernas, plurales y democráticas ${ }^{6}$.

Entre el paso del siglo pasado y el inicio del presente, encontramos dos estudios que ofrecen una síntesis de su posición hasta ese momento, destacables por ubicarse en una perspectiva que incluye los compromisos religiosos (respecto de los cuales Habermas se declara "unmusikalisch"). Por un lado, Mardones ${ }^{7}$ parte de una hipótesis central para Habermas: los principales aportes de lo religioso podrían subsumirse en una ética discursiva, aunque subsisten núcleos valiosos que la modernidad jamás podría conseguir, como son las cargas semánticas y motivaciones de esperanza y solidaridad. Mardones analiza el rol que todavía cabe a los elementos que se pierden, y vale la pena pensar desde esta perspectiva el trabajo posterior de Habermas. Por su parte, Estrada interpreta que la filosofía ofrecería legitimaciones argumentativas y las creencias religiosas motivaciones, y que en lo epistemológico el intento de traducir contenidos es valioso pero pierde los aspectos performativos de lo religioso. La conclusión es que ambos discursos sólo lograrían un diálogo con contenido material si se pudiesen vincular concepciones del bien y procedimientos de justicia, "contenidos sustancialistas de las tradiciones y la metodología argumentativa universalista". Pero al no suceder, las motivaciones que la religión ofrece no pueden alcanzar las pretensiones de validez epistémica y normativa de la argumentación filosófica. Por eso la

denotada por los mismos no es transferible de modo directo de un idioma a otro. En todo caso, podemos decir que la actividad del primero denota la confianza en una serie de afirmaciones que no son corroborables ni refutables con procedimientos intramundanos, mientras que la segunda incluye proposiciones sobre el mundo, validables a partir de los propios fenómenos.

3 Una secuencia clara del vínculo de Habermas con lo religioso, el secularismo y el postsecularismo puede encontrarse en Ortega-Esquembre y García-Granero (2019). Se muestra cómo en clave secular, Habermas atiende primero a la relación de emancipación y soteoriología; luego a la relación con la identidad y socialización (relacionada con el sentido de obligación normativa), y finalmente al vínculo de anamnesis y justicia con su teoría consensual de la verdad, la ética discursiva y la política deliberativa. A partir de estos tres momentos, los autores plantean una cuarta etapa caracterizada por una formulación postsecular debido a que encuentran una nueva sensibilidad de Habermas hacia lo religioso.

4 Jürgen Habermas, El futuro de la naturaleza humana (Barcelona: Paidós, 2002).

5 Giovanna Borradori, Jürgen Habermas y Jacques Derrida. Philosophy in a Time of Terror (Chicago: University of Chicago Press, 2003).

6 Jürgen Habermas, Israel o Atenas (Madrid: Trotta, 2001), 171. Jürgen Habermas y Josef Ratzinger, Entre razón y religión (México, FCE, 2008).

7José María Mardones, El discurso religioso de la modernidad. Habermas y la religión (Barcelona: Anthropos, 1998).

8 Juan Antonio Estrada, Por una ética sin teología. Habermas como filósofo de la religión (Madrid: Trotta, 2004 ), 218. 
legitimación filosófica exige a la religiones lingüistificar y traducir sus experiencias, aunque así nunca se exponga plenamente la experiencia vivida. Estas ideas permiten enfocar dos cuestiones centrales para Habermas: la hipótesis de la secularización en el marco amplio de la modernidad y la tarea de traducir los contenidos a un lenguaje secular. Ambas explican la matriz de su posición sobre el rol de lo religioso y los procesos de aprendizaje.

La premisa de la secularización es una característica básica de la modernidad. Más allá de las críticas y limitaciones de esta hipótesis, el vínculo de modernidad y secularización tiene un peso relevante en toda la obra habermasiana. El uso del término "postsecular" debe comprenderse desde la supervivencia de comunidades creyentes en el marco de comprensiones y justificaciones seculares, en un mundo comprendido desde la racionalización de las relaciones y las explicaciones, y la auto-obligación respecto de justificaciones racionalmente comunicables y aceptables ${ }^{10}$. La secularización y lo religioso significan modos diversos de comprender el funcionamiento de los sujetos en las sociedades, sus decisiones y fundamentos. Como con el funcionalismo en comunicación, Habermas opera respecto de la secularización un gesto análogo de aplicación, ponderación y transformación. En el paso del contexto secular al postsecular, éste no elimina a aquel, sino que asume algunas de sus características y reconoce que algunos pronósticos sobre el acabamiento de lo religioso resultaron inexactos. La secularización permanece como horizonte, pero incorpora la reflexión sobre la persistencia y los aportes de las religiones en la configuración de las sociedades contemporáneas.

Habermas reconoce a las religiones diversos roles sociales, que no se reducen a la cohesión grupal o legitimación pública del poder. Incluye el aporte a la discusión filosófica de contenidos como el valor y dignidad individual y universalizada de cada persona, que son de clara procedencia judeocristiana e inseparables de las instituciones nacidas en occidente ${ }^{11}$, aun cuando éstas afianzaron su injerencia en el marco laico de la modernidad. Así, el proceso moderno de secularización muestra la necesidad de pasar "desde el vocabulario de una comunidad religiosa determinada a un lenguaje universalmente accesible" 12 .

La racionalización que caracteriza diversos ámbitos de la modernidad también abarca la esfera religiosa. Habermas retoma a Weber sobre las pretensiones de validez interna de las creencias y su necesidad de responder a las coacciones racionales, como un proceso de aprendizaje de las religiones mismas y su progresiva concentración en cuestiones éticas, debido a que las creencias quedaron desfasadas respecto de los datos de las ciencias ${ }^{13}$. Así, el interés emancipatorio de auto-reflexión alcanza a las religiones en el contexto secular moderno, y vincula la secularización con la lingüistificación de lo religioso ${ }^{14}$, y muestra la modernización de su comprensión. Con esta la exposición de sus núcleos de sentido en un lenguaje comprensible por otros, se consolida un incremento de racionalidad sustentado en la distinción de tipos de pretensiones de validez según esferas que a menudo aparecen entremezcladas en el mundo de la vida.

9 José Casanova, Genealogías de la secularización (Barcelona: Anthropos y Universidad Autónoma de México, 2012).

10 Thomas Schmidt y Annette Pitchmann, Religion und Säkularisierung: Ein interdisziplinäres Handbuch (Stuttgart: Metzler, 2014), 20.

11 Jürgen Habermas, Pensamiento postmetafísico (Madrid: Taurus, 1990), 25.

12 Jürgen Habermas, Entre naturalismo y religión (Madrid: Trotta, 2006), 139.

13 Jürgen Habermas, Teoría de la acción comunicativa, Tomo 1 (Madrid: Taurus, 1999), 260.

14 Jürgen Habermas, Teoría de la acción comunicativa, Tomo 2 (Madrid: Taurus, 1999), 205. 
La racionalización y burocratización de las esferas del mundo de la vida antes inseparables sería un proceso de aprendizaje para la cultura, la personalidad y las instituciones ${ }^{15}$.

La Teoría de la acción comunicativa ya ve procesos de aprendizaje cuando las imágenes religiosas contribuyeron a desarrollar explicaciones y conceptos formales del mundo ${ }^{16}$, y respuestas argumentadas ante problemas como la teodicea y la justificación universalista de su ética ${ }^{17}$. Pero aunque la relación de conocimiento filosófico y discurso religioso aparece claramente entre los desafíos prácticos-cognitivos de las transformaciones modernas, y aunque Habermas admita que en la base de las instituciones modernas de derechos se hallan contenidos secularizados que originalmente eran religiosos, todavía no se elabora allí el proceso histórico de mutua incidencia como proceso de aprendizaje filosófico. ${ }^{18}$

Otro aspecto relevante del proceso de aprendizaje, con una lógica evolutiva que Habermas remite a Piaget y amplía al campo social, es su diferenciación entre ámbitos: cultura, sociedad y personalidad: "para tal diferenciación estructural habrá que postular procesos de aprendizaje si puede demostrarse que esa diferenciación supone un incremento de racionalidad"19. La "lingüistización de lo sacro" permite esa diferenciación y explica el rol legítimo de lo religioso en el contexto secular. Habermas ${ }^{20}$ vincula proceso de aprendizaje y evolución de imágenes religiosas, a partir de la doble necesidad de dar respuestas racionales (internamente coherentes, intersubjetivamente validables y consistentes con los conocimientos actuales) ante disonancias cognitivas y éticas, y de presentar esas justificaciones argumentativamente. Ambas tareas comienzan admitiendo que hay disonancias entre lo que las personas creen por su fe y las explicaciones logradas por los avances cognitivos. Así se explica no sólo el intento de armonizar creencias y conocimientos, sino también de elaborar un vínculo que mantenga la especificidad de cada ámbito. Habermas fundamenta así la tarea posterior de rastrear cómo, en interacción con los discursos religiosos, la filosofía tomó motivos y sensibilidades, les tradujo a un lenguaje prescindente de los compromisos de fe, e identificó en algunos de ellos la validez de un deber independiente de su contexto de origen. También reconocerá que hace falta una "compensación" (a menudo insatisfecha) cuando la "descontextualización" de los discursos sobre valores culturales, creencias, etc., le quita a las normas el tipo de soporte proveniente de la raíz cultural. ${ }^{21}$

Con estas premisas puede entenderse el aporte de También una historia, en tanto rastrea genealógicamente ese proceso de aprendizaje mutuo, elabora el modo en que se dio la respuesta a las disonancias cognitivas y prácticas, y reconstruye el paso de las justificaciones metafísicas a las seculares.

15 Habermas 1, 448s)

16 Habermas, Teoría de la acción comunicativa, 1, 101.

17 Habermas, Teoría de la acción comunicativa, 1, 260.

18 Sin embargo, una línea de interpretación continua como la de Conill (1996 y 2020), sostiene que la teoría de la acción comunicativa misma puede entenderse como una filosofía de la religión - o al menos un capítulo de la misma - ya que necesita recurrir al estudio de lo religioso para explicar el desarrollo y el estado de cuestiones como la racionalidad, la sociedad y el marco de la modernidad.

19 Habermas, Teoría de la acción comunicativa, 2, 205.

20 Habermas, Teoría de la acción comunicativa, 1, 101.

21 Habermas retoma repetidamente la pregunta de Böckenförde a fines de los '60 sobre cómo se sostendría el Estado liberal si se nutre de presupuestos heredados que él mismo no puede garantizar y que de hecho debería poner fuera de juego si es que ha de ser precisamente un Estado liberal. 


\section{1) Procesos de aprendizaje en También una historia de la filosofía}

¿Qué son los procesos de aprendizaje en una historia de la filosofía comprendida desde la relación de fe y conocimiento? "Comprendemos la dinámica de los procesos de aprendizaje como una elaboración de disonancias cognitivas que se dieron tanto del lado de la naturaleza como de la evolución social, o sea a partir de la confrontación entre, por un lado, las imágenes del mundo y las resistencias que las refutan de parte de la naturaleza, y por otro lado los desafíos de los conflictos y crisis similares de la integración social"22. Es una idea que atraviesa toda la obra: fe y conocimiento han establecido una interacción históricamente cambiante, que permitió a ambas consolidar procesos de aprendizaje, transformar sus respuestas y eventualmente volver sobre sí e indagar reflexivamente su auto-comprensión. A continuación se expondrán las características estructurales de los procesos de aprendizaje y luego el modo en que operan.

1. Estos procesos indican la capacidad incremental de explicar y relacionarse con el mundo en el campo epistémico, establecer procedimientos de legitimación de las decisiones en el campo práctico de la ética y la política, y exigir una coherencia (y eventualmente correcciones) a las creencias frente a los avances científicos y las demandas sociales. Incorpora progresivamente la conciencia del falibilismo de las posiciones y la conciencia de que los fines buscados y logros se dan por procesos de aprendizaje necesariamente cooperativos. Habermas muestra que en el paso de la antigua comprensión contemplativa del conocimiento a otra objetivante moderna y finalmente a una comprensión performativa contemporánea, pudo extenderse una idea de conocimiento que no sólo incluía los objetos del campo de las ciencias naturales modernas sino también historia, cultura y sociedad.

Habermas presenta la siguiente secuencia: la elaboración mítica de la era axial (800aC-200aC) inició en diversas culturas un movimiento de explicación y de generación de imágenes del mundo a partir del "complejo sacral" que coordina, con una explicación abarcativa, el conocimiento del mundo, la autocomprensión y la sensibilidad moral ${ }^{23}$. El discurso filosófico griego fue una de sus derivas más influyentes, analizando el mundo en tercera persona, universal y neutro. La edad media continuó esta posición, pero al incorporar ideas monoteístas como la finitud y teleología del mundo, las normas generadas por una voluntad divina, la libertad individual, la necesidad de relacionar coherentemente creencias con afirmaciones cognitivas, etc., mantuvo la visión ontológico-metafísica y al mismo tiempo dio pie a algunos de los cambios que impulsarían aspectos concretos de la modernidad (como por ej. el nominalismo y el énfasis de lo individual $)^{24}$. Los procesos de aprendizaje rescatan el "potencial de razón" de las imágenes del mundo y de las creencias religiosas, para luego, de camino al pensamiento postmetafísico, cuestionar su validez interna a partir de los estándares de racionalidad externos, contribuyendo así a un proceso que elimina aspectos inaceptables y sostiene los elementos con validez universal. La teología tuvo un potencial cognitivo, por su trabajo de explicación y revisión en vistas de una doctrina común, que pudiera justificarse como verdadera ante el conocimiento coetáneo. Según Habermas, esto muestra el carácter procedimental de este tipo de pensamiento y su justificación posterior, lo que no anula su determinación de origen y contenidos.

22 Jürgen Habermas, Auch eine Geschichte der Philosophie, Tomo 1 (Berlín: Suhrkamp, 2019), 135. Las traducciones pertenecen al autor.

23 Habermas, Auch eine Geschichte der Philosophie, 1, 175.

24 Habermas, Auch eine Geschichte der Philosophie, 1, 516 y 617. 
Durante la modernidad, el objetivismo y su modelo paradigmático de las ciencias naturales se nutrió de estas raíces para pensar al mundo objetivamente, en tercera persona aunque desde la interioridad de la primera, con una filosofía del sujeto ${ }^{25}$. Aparecieron límites y progresivamente se retomaron aspectos anticipados por performatividad y comunicación en la praxis religiosa, que sumados al nominalismo tardomedieval y a la conciencia del rol del lenguaje, posibilitarían un paradigma lingüístico-pragmático todavía vigente. Éste combina la segunda persona con la primera del plural, tomando las condiciones de reciprocidad comunicativa y las condiciones culturales y sociales de comunicación. La modernidad incluyó progresivamente como objeto de estudio a la cultura, la historia y la sociedad desde las prácticas de sus miembros ${ }^{26}$. Esto muestra la conciencia actual del vínculo entre ideas y contextos, hace que la filosofía tome a la modernidad misma como tema, y proponga una reconstrucción con pretensiones de validez legitimables más allá del contexto de surgimiento. En todo ese proceso las imágenes metafísicas del mundo y los contenidos religiosos posibilitaron sucesivas tareas cognitivas y funciones de vínculos culturales y sociales, que recién las ciencias humanas modernas tematizan ${ }^{27}$.

La vía occidental de los procesos de aprendizaje filosóficos es una reacción a las crisis de integración social y al crecimiento del conocimiento del mundo. Junto avance de la visión científica del mundo, "los conceptos metafísicos fundamentales, en los cuales las descripciones todavía estaban fusionadas con contenidos normativos y evaluativos, pierden su base; así se disuelve también la conexión proyectiva del 'mundo' aprehendido teóricamente con las connotaciones de la 'totalidad' abarcadora del mundo de la vida" ${ }^{28}$. Cae la imagen de totalidad y las narraciones y teologizaciones previas pierden su rol, lo que les lleva en el mejor de los casos a asumir esos aprendizajes y resignificar sus pretensiones de validez en un campo diverso al científico pero en necesario diálogo con él.

2. ¿Cómo operan los procesos de aprendizaje? Habermas evita reducir los procesos de aprendizaje a meras respuestas reactivas a impactos externos, porque las crisis no son disparadores exclusivos de procesos de aprendizaje convincentes. Un proceso de aprendizaje no es sólo una reacción ante una función alterada o crisis de supuestos (la caída del orden metafísico griego, del imperio, de la teología ante la ciencia, etc.). Es además la acción reflexiva de establecer justificaciones aceptables, más convincentes cognitivamente y más eficaces socialmente para conseguir el consenso libre de las personas, que explican mejor los fenómenos y son más coherentes con la auto-reflexión subjetiva. Por via contraria Habermas argumenta presentando las respuestas de la primera mitad del s. XX, que considera incongruentes con la modernidad, porque no abordan la pregunta: “ ¿se podrían haber impuesto las vías teóricas hacia el pensamiento postmetafísico, que en cada caso remiten a la crisis del presente, más bien como resultados de procesos de aprendizaje intrínsecamente convincentes?" ${ }^{29}$. Las respuestas reactivas a la crisis, ${ }^{30}$ que la comprenden sólo como ruptura de un orden anterior, son incapaces de ver ahí un proceso de aprendizaje convincente en sí mismo. Con Blumenberg, Habermas considera que es una justificación racional inmanente y suficiente de

25 Jürgen Habermas, Auch eine Geschichte der Philosophie, Tomo 2 (Berlín: Suhrkamp, 2019), 137.

26 Habermas, Auch eine Geschichte der Philosophie, 2, 375.

27 Habermas, Auch eine Geschichte der Philosophie, 1, 36.

28 Habermas, Auch eine Geschichte der Philosophie, 2, 205.

29 Habermas, Auch eine Geschichte der Philosophie, 1, 38.

30 Excede a este trabajo la posibilidad de reconstruir los síntomas epocales que identifican Schmitt, Heidegger, Strauss, y Löwith, y cómo sus respuestas son incapaces, según Habermas, de dar una respuesta racional reconstructiva de los pasos históricos del aprendizaje y conocimiento. cf. Habermas, Auch eine Geschichte der Philosophie, 1, 40-74. 
los avances del aprendizaje, el mero hecho de que se necesite revisar errores. Pero eso todavía no explica porqué hemos aceptado, generalizado y legitimado esas prácticas cognitivas, de modo que aceptamos la validez de las afirmaciones independientemente de su procedencia. Tampoco explica la persistencia de las creencias, ni cómo asumieron dispositivos del discurso moderno. Finalmente, tampoco responde a la pregunta de cómo las convicciones o creencias mutan hacia justificaciones allende los contextos de origen. Para Habermas esto sólo es posible cuando el aprendizaje sirve tanto para reconstruir el origen de de los contenidos ${ }^{31}$ como para elaborar una auto-reflexión del proceso y mostrar con premisas seculares los resultados de esas nociones, sin requerir una posición creyente para asumir su validez. ${ }^{32}$ Recién desde esta posición se pueden reconstruir y comprender los principales hitos cognitivos en filosofía, que permitieron procesos de aprendizaje con esas interacciones.

Las crisis "muestran cuándo ya no se cumplen las condiciones para una integración social suficiente", aunque son más que un mero déficit de integración. ${ }^{33}$ Hay una productiva aunque tensa relación entre las adaptaciones sistémicas a las crisis y los procesos de aprendizaje endógenos. Los procesos de aprendizaje sociales y cognitivo-morales transforman la comprensión de sí y del mundo, generando la posibilidad de cambios institucionales. Ya en el complejo sacral se inicia una tensión entre, por un lado, el mito que produce categorías de explicación del mundo y permite procesos de aprendizaje (con posibles disonancias), y por otro el rito que de alguna manera estabiliza la imagen del mundo y alcanza recursos profundos de solidaridad comunitaria. ${ }^{34}$ Los procesos de aprendizaje al mismo tiempo introducen disonancias (por nueva información), generan el desfasaje en la adaptación sistémica, y permiten romper el estancamiento de los sistemas.

Una operación fundamental de los procesos de aprendizaje en relación al vínculo de creencias y conocimientos es recuperar "contenidos de verdad" que pueden sostenerse de modo independiente de la fe y que sirven a los dos objetivos de acumular conocimiento sobre el mundo y permitir una evolución social que supere las crisis. En reverso, también procesan los impactos que esas crisis y conocimiento ampliado tienen sobre las creencias mismas. Esto lo vemos ya en el primer gran bloque que Habermas estudia, el surgimiento de las "imágenes del mundo" a partir del "complejo sacral" (prácticas de salvación más imágenes omnicomprensivas). Son las primeras respuestas a las preguntas sobre el mundo y su conocimiento (también una teoría germinal sobre la legitimación). La limitación progresiva de las esferas y su validez sólo se comprenden desde su evolución histórica.

3. Finalmente, es preciso formular la pregunta por el rol de la filosofía misma respecto de los procesos de aprendizaje. Al enfocar su historia desde la relación de fe y conocimiento como propulsora de procesos de aprendizaje, Habermas muestra que la filosofía subsiste independiente de ambos, en su tarea de reconstrucción, evaluación y legitimación. Ese trabajo no corresponde a las ciencias, que atienden una esfera definida de objetos, mientras que la filosofía analiza los procesos de aprendizaje correspondientes,

31 Entre los múltiples contenidos que Habermas reconstruye mencionemos la separación de la ética de la voluntad libre monoteísta de la ontología de los bienes griega, la búsqueda de liberación del dominio mediante una noción de salvación, la noción del deber autónomamente asumido, la separación de propiedad y dominio, etc.

32 Habermas, Auch eine Geschichte der Philosophie, 1, 67-71.

33 Habermas, Auch eine Geschichte der Philosophie, 1, 140.

34 Habermas, Auch eine Geschichte der Philosophie, 1, 294. 
y explica qué significa lo "propio" de nuestra auto-comprensión. ${ }^{35}$ En este sentido, filosofía y teología heredan del movimiento ya nacido en la era axial el trabajo de reflexión de segundo nivel.

En el discurso occidental sobre fe y conocimiento, esa elaboración autorreflexiva tuvo inicialmente la forma de una justificación de la creencia. Pero desde la modernidad la filosofía pasó de la defensa al ataque. Con las ciencias modernas y el contexto capitalista, no sólo se ve que no hay una conexión directa entre el conocimiento teológico y el científico, sino que tampoco hay una fusión entre reflexión filosófica y procesos de aprendizaje científicos. Mientras que en el ámbito teórico las ciencias no requirieron una vuelta reflexiva sobre sus propios procedimientos, el requisito sí parece mantenerse en el vínculo de filosofía y teología (entre ambas y cada una respecto de sí).

La era axial había permitido impulsos cognitivos notables. Con las imágenes del mundo comienza también una distinción de las grandes civilizaciones, y se manifiesta su capacidad de estabilizar las comprensiones del mundo y de revolucionarlas. ${ }^{36}$ Por su estructura dualista explica lo inmanente al mundo, distanciación mediante, por una abstracción que va más allá de las narraciones mitológicas. Se superan progresivamente la magia y la idea de influencia sacrificial so bre lo divino, av anza una progresiva desacralización del mundo y del dominio. Los poderes de la salvación y su vínculo con la justicia, originariamente fijados en quien detentaba el poder, son extroyectados a un poder fundante, que recién desde su acción justifica las acciones mundanas. ${ }^{37}$ Ese desencantamiento del mundo tendrá importantes efectos en la política. Las imágenes religiosas del mundo no pierden su valor, porque en el "mundo de la vida" los sujetos mantienen performativamente unidas prácticas y sentidos. Pero la apelación a una perspectiva trascendente genera un modelo fuerte de teoría y de verdad, que con la contemporaneidad deviene autoconsciente de su falibilismo y del carácter performativo, lingüístico y práctico, de sus resultados.

A partir de la era axial, particularmente desde la reflexión filosófica, se logra un a diferenciación progresiva de ámbitos, que guía procesos de reflexión y de aprendizaje en diferentes direcciones: "la mirada teórica del cosmos inicia un contacto estrecho entre la búsqueda de salvación y la búsqueda de conocimiento del mundo, mientras que la mirada moralmente sensible sobre el destino histórico y la constitución social del colectivo y de sus miembros individuales conduce el esfuerzo de conocimiento desde el mundo hacia el trasfondo performativamente presente del mundo de la vida como fuente existencial de la experiencia". ${ }^{38}$ La cuestión de la salvación vira hacia lo moral (incluyendo el conocimiento moral, las obligaciones, el universalismo, etc.), mientras que el conocimiento científico del mundo adquiere una independencia cada vez mayor.

En el cristianismo este proceso es patente, en tanto la auto-reflexión filosófica le lleva a coincidir en la independencia del mundo, su conocimiento y los métodos que le son pertinentes, así como también a la necesidad de vincular y actualizar sus creencias y valores con esos nuevos conocimientos. Esta necesidad de comunicar tradiciones distintas da al cristianismo cierta "flexibilidad hermenéutica" respecto de los

35 Habermas, Auch eine Geschichte der Philosophie, 1, 190.

36 Habermas, Auch eine Geschichte der Philosophie, 1, 307.

37 Habermas, Auch eine Geschichte der Philosophie, 1, 463.

38 Habermas, Auch eine Geschichte der Philosophie, 1, 475. 
procesos de aprendizaje. ${ }^{39}$ La interacción occidental de fe y conocimiento obliga al cristianismo a una "doble auto-reflexión": por un lado, la cuestión hermenéutica confronta la elaboración teológica cristiana y los antecedentes bíblicos hebreos; por otro, la discusión experta con las teorías cosmológicas desafían las prerrogativas de lo divino, al punto que la ciencia moderna prescinde de cualquier hipótesis divina.

La filosofía al mismo tiempo opera y reconstruye la transformación de las interpretaciones religiosas y metafísicas del mundo por presión del saber acumulado intramundano. Dichas interpretaciones fueron conducidas también a procesos profanos de conocimiento por el trabajo filosófico. El saber empírico moderno y el rol de las ciencias naturales y formales, así como las capacidades técnicas, exigieron reformar radicalmente la comprensión metafísica del mundo y adaptar las interpretaciones religiosas. Si las imágenes del mundo religiosas y metafísicas cumplían funciones de integración social y superación de las disonancias cognitivas y prácticas, el avance del conocimiento científico moderno condujo a que muchas de esas funciones fuesen suplidas por otros dispositivos.

El aprendizaje nacido de la relación de fe y conocimiento no careció de sinuosidades. Un hito es el protestantismo, cuyo origen muestra una mayor (aunque no voluntaria) adaptación de sus motivos a las condiciones modernas. "Irónicamente" - dice Habermas - "precisamente la doctrina teocéntrica de la entrega incondicional del ser humano a Dios", conduce a la "emancipación de la fe respecto de la metafísica" y "abre la puerta al giro antropocéntrico e la filosofía", y por ende "inaugura el pensamiento postmetafísico". ${ }^{40} \mathrm{Al}$ haber perdido Dios el rol de referencia central de ese sistema, su lugar paradigmático es reemplazado por la relación sujeto-objeto, y eventualmente da lugar a las dos corrientes principales de la epistemología moderna que nacen con Hume y Kant, y acompañan la progresiva independencia de las ciencias naturales. Concluye así la era de la imagen del mundo, aunque hasta el romanticismo se sostiene la idea de explicar el mundo en su totalidad.

Si bien la filosofía fue influida por los modos de conocer paradigmáticos de cada época - como la contemplación antigua o el objetivismo científico moderno - al mismo tiempo pretende distanciarse de esa influencia para analizarla. En el presente, el giro pragmático-lingüístico hace reconocer tanto la dimensión performativa como el empoderamiento efectivo de los sujetos, que no sólo acceden a conocimientos que les permiten ser eficientes en el mundo sino que además adquieren socialmente un "poder" de actuación. Pueden reproducir la sociedad y sus propias vidas, participando de los procesos cognitivos sociales y morales, asumiendo operativamente la perspectiva ajena en situaciones de disputas, $y$ disponiendo de los conocimientos y procedimientos necesarios para los momentos de conflicto. ${ }^{41}$

Las interpretaciones míticas tenían una función cognitiva que les abría a procesos de aprendizaje y al reconocimiento de las disonancias cognitivas, lo que a su vez condujo a nuevos aprendizajes. Este falibilismo debilitó progresivamente las imágenes del mundo frente a otras formas más pragmáticas del saber del mundo a la hora de estabilizar las sociedades. Por eso, el mito primero y las configuraciones religiosas y teológicas después, fueron ambivalentes. Las narrativas y los ritos pudieron adaptarse de las disonancias del saber mundano, al precio de cambiar sus pretensiones de validez y reubicar sus discursos

39 Habermas, Auch eine Geschichte der Philosophie, 1, 532.

40 Habermas, Auch eine Geschichte der Philosophie, 2, 13.

41 Habermas, Auch eine Geschichte der Philosophie, 1, 138. 
en otro plano. Habermas ve que el lazo funcional es insuficiente para explicar la simbiosis persistente entre interpretaciones religiosas del mundo y praxis rituales, que les otorga a sus miembros un tipo de solidaridad no accesible por otros procedimientos sociales. ${ }^{42}$ La posición performativa permite ver qué aprendizajes todavía pueden sacarse de las experiencias religiosas, y el tipo de pretensiones que sus afirmaciones pueden mantener luego de pasar por la crítica del conocimiento científico y las exigencias de lingüistificación de los contenidos, autonomía de los sujetos y autorreflexividad frente a los avances cognitivos.

\section{2) Procesos de legitimación en También una historia de la filosofía}

Los procesos de aprendizaje no se han dado sólo por situaciones de crisis entre creencias y nuevos conocimientos del mundo, sino también en las relaciones sociales. También aquí es central la tarea de reflexión sobre las justificaciones y aceptabilidad de las afirmaciones. Pero el tipo de conocimiento requerido tiene características propias, porque las capacidades culturales de aprendizaje dependen de interacciones simbólicamente mediadas. ${ }^{43}$ Por eso las imágenes del mundo y las creencias religiosas fueron tan influyentes en las legitimaciones prácticas, y al decaer su influencia fueron reemplazadas, según Habermas, por la estructura comunicativa y consensual de la comunicación. ${ }^{44}$

Habermas parte de los estudios que muestran en el neolítico sociedades organizadas por parentesco, poseedoras de una comprensión simbólica e intercambios materiales. Luego, las primeras sociedades estatales se consolidan con la mitología y la escritura, y comienzan a separar funciones políticas y religiosas. La formación de los antiguos reinos y la progresiva diferenciación de salvación y dominio, inicia el ejercicio de legitimar lo político con doctrinas metafísicas y religiosas. Finalmente, las sociedades modernas funcionalmente diferenciadas instauran una separación y tensa interacción entre la administración estatal y una economía capitalista autonomizada, y entre religión y administración política, conocimiento científico y moral laica. ${ }^{45}$ La complejización social, la separación de esferas y pretensiones de validez, y la ampliación de perspectivas de conocimiento moral, llevan a atender los cambios y aspectos compartidos en las diversas esferas. "La vinculación de los procesos de aprendizaje con el conocimiento tomado como válido alcanza todos los aspectos de la sociedad", incluidos el derecho y la moral. ${ }^{46}$ Los sujetos contrariados por contingencias prácticas buscan soluciones e innovan la sociedad,

42 Habermas, Auch eine Geschichte der Philosophie, 1, 270.

43 Habermas, Auch eine Geschichte der Philosophie, 1, 227.

44 Esto permite dar un paso más en la larga indagación de Habermas acerca de la legitimidad y los modelos - muchas veces en tensión - que la fundamentan. En este sentido, Facticidad y validez mostraba ya cómo en una sociedad sin una posición metasocial de fundamentación, por ej. religiosa, debe sin embargo mantener la confluencia de la positividad con la aceptación social, antes garantizada por otro orden simbólico. Además, Habermas distingue allí algo cuyas fuentes reconstruye en También una historia, o sea, por un lado, la legitimidad del derecho y su relación con la legitimación en su construcción, y por otro la legitimidad del orden del poder político (Habermas, Facticidad y validez, 199ss). Lo valioso de También una historia es mostrar cómo la tensión con el monoteísmo - a menudo usado para ambas justificaciones - terminó conduciendo a la posición postmetafísica actual y su requisito de otra fuente de legitimación.

45 Habermas, Auch eine Geschichte der Philosophie, 1, 144.

46 Habermas, Auch eine Geschichte der Philosophie, 2, 584. 
amplían los horizontes de expectativas, reconocen nuevos límites, y recomienzan el ciclo. La filosofía revela su historia en ese proceso, al indagar las injerencias de lo religioso en esas justificaciones prácticas.

1. En el campo político, desde las imágenes del mundo vemos dos elementos constituyentes: "de un lado el poder de dominio con jurisdicción y organización de la administración, y por el otro el poder del sacerdocio" que dispone del culto, de la salvación y la legitimación del dominio. ${ }^{47}$ El "complejo sagrado" vinculó estructuralmente los diversos sectores sociales con la integración social de la religión y su reunión de ritos y mitos (e interpretaciones). Esta integración estabilizaba y daba garantías en la crisis. Pero varía con la complejidad social, pasando de las relaciones de parentesco al surgimiento del sacerdocio como institución separada del gobierno político, y finalmente depurando teóricamente su actividad de legitimación del poder. ${ }^{48}$

Las narraciones míticas avanzan al no legitimar la autoridad por relaciones personales, sino abstrayendo la noción de "autoridad política de un gobernante que genera el derecho". Aunque habitualmente se daba por un vínculo dinástico con los dioses, esto operó cierta "racionalización" del mundo de los dioses. Con la simbiosis de filosofía y monoteísmo hay un salto cualitativo: la justificación del poder requiere un principio externo, que separa definitivamente salvación y dominio (antes personificados y unidos, por ej. en el Emperador). ${ }^{49}$ Sucede en política algo análogo a la escisión entre salvación y justicia en la moral: se disuelve una identidad y quienes detentan el poder pierden su invulnerabilidad y necesitan legitimación. Avanza la diferenciación medieval entre sacerdotium y regnum, que no sólo relaciona conocimiento práctico y creencia, sino que configura la filosofía política hasta la modernidad. ${ }^{50}$ Más allá de sus lados oscuros, la iglesia funcionó como contrapunto de los poderes mundanos, postulando un contraste con el ideal, que "una y otra vez condujo a canales de transformación social". ${ }^{51}$

En los aprendizajes nacidos de las imágenes del mundo se acumulan conocimientos del mundo y de la sociedad, de las respuestas y sus resultados. "En tanto la metafísica recién surge en las sociedades estatalmente organizadas de la era axial, la elaboración reflexiva de temas de integración social asume ante todo la forma de una teoría política" que legitima el dominio. ${ }^{52}$ En occidente la teología incorporó esa tarea con la reflexión filosófica. Con matices, ese modelo duró hasta el secularismo, cuando la justificación volvió a recaer en el campo de la filosofía misma, sobre todo en las democracias liberales, donde asume "la fundamentación por el derecho racional de normas constitucionales - y con eso también una función vital para la integración política.". 33

Desde la ilustración, la filosofía toma dos vías: "la primera vincula a la filosofía, después de su giro crítico hacia lo religioso, con la ciencia metodológicamente independizada; y luego con las nuevas funciones sociales cumple su rol pedagógico popular en la naciente sociedad burguesa, su rol crítico del dominio en

47 Habermas, Auch eine Geschichte der Philosophie, 1, 637.

48 Habermas, Auch eine Geschichte der Philosophie, 1, 141.

49 Esta discusión continuó en el tiempo, como se ve en Agustín, Gregorio Magno y Carlomagno. Habermas, Auch 1, 601.

50 Habermas, Auch eine Geschichte der Philosophie, 1, 617.

51 Habermas, Auch eine Geschichte der Philosophie, 1, 635.

52 Habermas, Auch eine Geschichte der Philosophie, 1, 73.

53 Habermas, Auch eine Geschichte der Philosophie, 1, 73. 
el ámbito público político, y su rol de legitimación en el Estado constitucional". ${ }^{54} \mathrm{~A}$ la par se opera el paso de una filosofía del sujeto a un modelo hermenéutico de comprensión ubicado en las relaciones sociales e intersubjetivas. El paso de Kant a Hegel es el paso del sujeto ahistórico del conocimiento a un sujeto ya enmarcado por cultura y sociedad. Para Habermas esta innovación avanza con el pragmatismo: las capacidades subjetivas "ya no se explican a partir de la introspección de procesos interiores sino como resultado de procesos de aprendizaje por una participación en prácticas sociales ya existentes" ${ }^{55}$ No basta el análisis cultural sino que hay que asumir la perspectiva objetivante del ciudadano en su rol de co-legislador democrático. Recién ahí tematiza su entorno y lo hace objeto de discusión y transformación política.

Habermas muestra como consecuencia contemporánea de la legitimación política, que la participación como posibilidad de solucionar problemas en estados democráticos reemplazó la solución cultural de Hegel por la interacción comunicativa. ${ }^{56}$ Ya la democracia griega incluía como proceso de aprendizaje la reflexión sobre reglas institucionales basadas en la experiencia, a diferencia del pensamiento a partir de principios consolidados, característico de la era axial. ${ }^{57}$ Las reformas institucionales surgen siempre de situaciones conflictivas, y la tarea filosófica de reflexionar sobre esos procesos combina resultados de la experiencia práctica, principios racionales, y autoreflexividad respecto de los procesos. Pero en el período intermedio, el monoteísmo sostiene el doble movimiento de configurar procesos y atender a principios. Así, el avance hacia lo normativo genera una dinámica que analiza las relaciones sociales concretas y sus problemas de justicia desde la perspectiva de un "contenido normativo inagotable de derechos fundamentales y exigencias no saturadas de justicia." ${ }^{8}$ No es casual que la consciencia histórica indague las transformaciones y sus efectos en las instituciones, pero también las regresiones y alienaciones, porque son procesos falibles de los sujetos socializados mismos.

La larga construcción de las ideas de autonomía, de libertad y su encarnación institucional en la política permite ver la relación progresivamente universalizable de subjetivación y socialización. La autonomía se muestra en las huellas históricas, que como procesos de aprendizaje morales y prácticos "se encarnan en el crecimiento de libertades institucionalizadas y hoy sobre todo en las prácticas y las garantías de los estados constitucionales democráticos" ${ }^{59}$ Aunque la legitimación actual de las decisiones políticas asume como fuente a los ciudadanos, Habermas recupera la idea de Adorno que no hay contenido teológico que no sobreviva de una manera transformada. Así migran los contenidos teológicos al pensamiento profano, en un proceso de aprendizaje filosófico que, al mismo tiempo, nos muestra cómo hemos justificado el uso de la libertad racional a lo largo del doble proceso de socialización e individuación.

2. En el terreno moral debe verse el proceso de justificación de las normas, y cómo mantienen un contenido cognitivo diverso de las afirmaciones científicas, con un procedimiento enfocado en la justicia y desprendido de las doctrinas salvívicas.

54 Habermas, Auch eine Geschichte der Philosophie, 2, 216.

55 Habermas, Auch eine Geschichte der Philosophie, 2, 528.

56 Habermas, Auch eine Geschichte der Philosophie, 2, 533.

57 Habermas, Auch eine Geschichte der Philosophie, 1, 415.

58 Habermas, Auch eine Geschichte der Philosophie, 2, 554.

59 Habermas, Auch eine Geschichte der Philosophie, 2, 806. 
En las culturas antiguas lo que llamamos conciencia moral no nace con la religión sino en la elaboración de los conflictos prácticos. Se diferencian los juicios sobre lo justo a partir de las experiencias cotidianas, independientemente de las imágenes y narraciones religiosas. ${ }^{60}$ Las narraciones míticas y las elaboraciones teológicas posteriores unifican $\mathrm{l}$ as $\mathrm{d}$ os $\mathrm{d}$ imensiones $\mathrm{d}$ e $\mathrm{j}$ usticia y $\mathrm{s}$ alvación. $\mathrm{L}$ a $\mathrm{r}$ acionalización $\mathrm{d}$ e $\mathrm{l}$ as imágenes del mundo y la fuerza vinculante del mito y el rito contribuyeron atribuyendo fuerza convincente y explicaciones morales para legitimar decisiones, integrar y estabilizar a la sociedad y a las experiencias individuales. ${ }^{61}$ Se ontologiza y moraliza lo sagrado, teniendo por paradojal consecuencia que se mundanizan las entidades y acciones, las cuales para su justificación $\mathrm{c}$ omienzan a $\mathrm{r}$ equerir $\mathrm{d}$ e u na legitimación trascendente. Progresivamente se diferencian los juicios sobre lo justo a partir de las experiencias cotidianas, independientemente de las imágenes religiosas del mundo. ${ }^{62}$ Esta posibilidad de distinguir dimensiones ha sido un elemento clave para las transformaciones postmetafísicas, al separarse los criterios procedimentales de justicia de la validación que habían obtenido en las narraciones religiosas abarcativas.

En paralelo, otros componentes éticos vinculados con la interpretación del destino personal en situaciones críticas significaron u $\mathrm{n}$ i mpulso h acia o tros p rocesos d e a prendizaje: "en e l c urso d e l a p rogresiva universalización e individualización de las representaciones de la justicia así como de la correspondiente interiorización de la reflexión ética, también el saber moral-práctico, alimentado de experiencias profanas, despliega su poder explosivo para la forma de pensamiento mítico, que ata a lo concreto y convencional". ${ }^{3}$ La idea universalista de justicia, primero extendida gracias al razonamiento religiosamente vinculado, se benefició de ese mismo proceso para desligarse de sus vínculos contextuales históricos, y proponerse con una validez que excede a las comunidades de pertenencia por creencia, cultura, etc.

Un eslabón fundamental es el paso de la filosofía griega - cuya acción de contemplar la naturaleza derivaba, en lo práctico, en identificar el bien característico para el ser humano - a la simbiosis con el cristianismo - que con su herencia judía comprendía deontológicamente la moral como resultado del cumplimiento del mandamiento de origen divino. Platón ya inició la "moralización" de lo divino, que exige un tipo de vida virtuosa y adecuada a la naturaleza para elevarse a la contemplación plena. ${ }^{64}$ El cristianismo toma la noción de obligación del antiguo testamento e introduce tres tensiones: una intra-religiosa entre la ética de la ley y la ética del amor, otra extra-religiosa entre las creencias y la filosofía, que le provee de argumentos racionales y universalizables para su teología, y finalmente existencial, entre la validez del deber reconocido y la voluntad a menudo débil de seguirlo. ${ }^{65}$ Lo continuo es que la conciencia moral deviene individualizada e interior.

El cristianismo también hace aportes en torno a la auto-limitación de las afirmaciones, como cuando por la noción de pecado Agustín pasa de considerar al cristianismo la filosofía más acabada a darle un estatuto provisorio. ${ }^{66}$ Con la escolástica, se ontologiza la ética de bienes aristotélica y la eleva hasta el ethos

60 Habermas, Auch eine Geschichte der Philosophie, 1, 304.

61 Habermas, Auch eine Geschichte der Philosophie, 1, 147.

62 Habermas, Auch eine Geschichte der Philosophie, 1, 304.

63 Habermas, Auch eine Geschichte der Philosophie, 1, 304.

64 Habermas, Auch eine Geschichte der Philosophie, 1, 450.

65 Habermas, Auch eine Geschichte der Philosophie, 1, 625.

66 Habermas, Auch eine Geschichte der Philosophie, 1, 561. 
vinculante cristiano, algo que según Habermas desde la perspetiva actual sería un retroceso, pero que en clave del cognitivismo moral significó un avance hacia la modernidad, porque busca dar argumentos racionales desligados del complejo sacral y porque plantea la cualidad moral desde la primera persona del actuante. La llegada del nominalismo comienza un cambio de paradigma que, paradojalmente, busca afirmar la potestad divina rompiendo con el orden ontológico del mundo y la epistemología metafísica, lo que moralmente conduce a una interpetación decisionista (Ockham), y a dar cuenta de la individualidad subjetiva y del rol fundamental de su voluntad (Duns Escoto). ${ }^{67}$

A partir de la modernidad, la nueva física continúa la ruptura que rompe la fuente "natural" del derecho natural y la moral que lo sostenía. El eje en la libertad de la voluntad y la racionalidad de los criterios de decisión ponen fuera de juego toda ética de bienes. Pero Habermas muestra que el sujeto trascendental kantiano y la autarquía de su razón no están a salvo de las influencias del mundo. No explica el origen contextual de su sentido moral del deber, sino que lo toma como algo dado. Y "en el paso histórico del derecho natural cristiano al derecho racional puede verse que el concepto universalista de la justicia deontológicamente vinculante surgió de la concepción más compleja de una justicia salvífica desde la era axial, y por ende del complejo sagrado". ${ }^{68}$ Pero Kant disuelve esta relación histórica, poniendo lo sagrado en el ámbito del sinsentido ceremonial, y a diferencia de Hegel no ve allí ningún resto de contenido racional. Por eso "la moral racional tiene el problema que con la desacralización de los mandamientos divinos no remite al núcleo sobrio de la pregunta de si la fuerza motivacional de los buenos fundamentos pueden - y en qué medida - reemplazar la fuerza vinculante de los mandamientos divinos". ${ }^{69}$ La discusión moral abandona definitivamente el plano del bien y la soteriología, y se ajusta a la pregunta por lo justo.

El avance del conocimiento científico hace caducar el marco de los conceptos metafísicos, que unían descripciones del mundo y valoraciones de comportamientos. Se rompe la relación intrínseca entre los sujetos y el mundo como totalidad. Los sujetos ya no pueden configurar una "imagen" de una totalidad abarcativa. Desde la modernidad asumen un lugar con derecho propio la sociedad y la cultura, como objetos que pueden configurarse para mejorar a una humanidad ilustrada. Pero no es fácil el paso de los sujetos de una época en que el mundo se comprendía desde imágenes abarcativas a otra dominada por las ciencias y disgregada. Vale preguntar: "si es que solo se puede hacer ciencia seria desde una posición objetivante, ¿cómo se ha de tratar con los objetos éticos y políticos, morales y jurídicos, y también estéticos, que hasta entonces habían sido tratados desde una perspectiva normativa?"70 Así se puede ver un último paso en el recorrido hacia el pensamiento postmetafísico con la diferenciación entre, por un lado, los discursos morales que buscan los fundamentos procedimentalmente validados de las normas y derechos que pueden reclamar validez independiente de las comprensiones del mundo, y por otro los discursos éticos, que se arraigan todavía en las orientaciones valorativas marcadas por pertenencias, cosmovisiones, creencias, etc.

Una dificultad vinculada que Habermas identifica alude al origen de la motivación, habiendo caído el sentido trascendente de lo religioso. En el caso de Kant, el sujeto trascendental encontraba una fuerza de

67 Habermas, Auch eine Geschichte der Philosophie, 1, 765.

68 Habermas, Auch eine Geschichte der Philosophie, 2, 369.

69 Habermas, Auch eine Geschichte der Philosophie, 2, 369.

70 Habermas, Auch eine Geschichte der Philosophie, 2, 206. 
mejoría continua con el despliegue de la razón. Pero si la teoría trascendental del conocimiento ponía sociedad, cultura e historia del lado de los fenómenos, no había estímulo para que el sujeto inteligible se anime a partir de los procesos de aprendizaje de la humanidad. Por eso, Habermas emprende una revisión no ortodoxa a partir de la función de auto-comprensión del pensamiento postmetafísico en su paso por Kant. La acción moral implica también una mejora moral de sí, lo que nos "incluye en un proceso moral que abarca a la humanidad como totalidad" en un avance de lo peor a lo mejor. ${ }^{71}$ Es un potencial epistémico ubicado tanto en la comunicación de la segunda persona como en la participación de la primera del plural, donde se puede asumir la reciprocidad e intersubjetividad en los procedimientos dedicados a descubrir los cursos justos de acción. Este largo aprendizaje de legitimación moral postmetafísica se nutre de antiguas posiciones cuyos contextos epocales han desaparecido, pero se han mostrado sostenibles sin ellos. Así, los discursos morales sobre normas en el marco postmetafísico se legitiman no desde el recurso a las orientaciones éticas de valores sino por ampliación de un nosotros participativo donde los sujetos, más allá de las propias comprensiones del mundo, legitiman sus posiciones desde la validez de las normas como partícipes de su construcción y en vistas de sus efectos. ${ }^{72}$

3. En el campo del derecho, Habermas encuentra algo específicamente occidental e inseparable de la reflexión filosófica sobre creencia y conocimiento. La "incondicionalidad" de la ley judía, la ética de bienes griega, y el derecho civil romano, no basado en derechos subjetivos sino en el ethos social estatal, configuran una constelación única. El cristianismo, originado en sectores marginales, exige progresivamente integración, vincula individualidad y universalidad, y lleva primero a romper la simbiosis imperial de salvación y dominio, y a proponer un orden legal desde otras fuentes, que generará la doctrina del derecho natural. ${ }^{73}$

En la interacción con la tradición jurídica romana y la progresiva elaboración del derecho canónico, la filosofía identifica contenidos y modelos discursivos que dieron lugar a una comprensión cada vez más autónoma del derecho, que debió sostener tensiones internas y al mismo tiempo justificar progresivamente un discurso igualitario y universalista. El derecho natural, a su vez, es transformado desde la modernidad desde la perspectiva de los sujetos libres que se asocian, y origina el derecho racional, lo que hace que filosóficamente se advierta la progresiva autonomía del derecho positivo. Las personas jurídicamente reconocidas y políticamente asociadas pueden repartir los derechos que les competen y fundamentar de modo legítimo las leyes que los regulan.

Los contenidos de fe incitan transformaciones jurídicas. A diferencia de Foucault, Habermas sostiene que la idea igualitaria del juicio final tiene efectos en el desarrollo del derecho universal, contrapuestos al derecho germánico clasista y sexista. ${ }^{74}$ En el medioevo subsiste la determinación de los derechos de justicia y dominio según jerarquía social, pero tanto la tensión entre poderes como entre órdenes legales progresivamente más abarcativos, prepara el terreno para una estructura legal formal universalizable. Es central el rol del derecho canónico desde las reformas del s. XIII: se fortalece el derecho civil, se reforma el derecho burgués, pero sobre todo el derecho canónico influye en el desarrollo político, económico y

71 Habermas, Auch eine Geschichte der Philosophie, 2, 331.

72 Habermas, Auch eine Geschichte der Philosophie, 2, 786.

73 Habermas, Auch eine Geschichte der Philosophie, 1, 525.

74 Habermas, Auch eine Geschichte der Philosophie, 1, 646. 
cultural. La Iglesia y sus instituciones asume esas transformaciones en su filosofía: separa territorio y dominio, fundamenta aun más la secularización del poder público y formula al derecho canónico con algunas características fundamentales para el Estado moderno y las constituciones estatales. Además, las transformaciones legales-eclesiásticas se entienden como autonomía auto-legisladora y como institución independiente de las determinaciones coyunturales, algo cercano al modelo de las constituciones modernas. ${ }^{75}$

Herederos del derecho romano, los juristas hasta el s. XIII otorgan al Código Justiniano un valor ejemplar, pero vinculándolo progresivamente con la praxis real de las ciudades y los conflictos, de modo tal que comienza una elaboración argumentativa propia que excede la glosa y la mera aplicación. A partir de la simbiosis con creencias monoteístas aparece la cuestión de la ley natural y su relación con la divina. Se distingue ad extra el derecho respecto de la ética y ad intra entre ius y lex. Ya la evolución de la idea de "ley natural" al "derecho natural" significó asumir una perspectiva con la cual aportar a todos las positivaciones y veredictos jurídicos un contenido racional. El uso separado de lex y ius permitió pensar un sustento normativo independiente de sus positivaciones, que a la vez las legitima desde un orden interno (en sintonía con la ley divina). La consolidación en paralelo del derecho canónico y el ius civile no sólo significó separar jurisdicciones y potestades, sino además hace que la religión cristiana asuma características modernas de administración. ${ }^{7677}$

Para Tomás de Aquino, la separación aristotélica entre reflexión ética sobre la vida buena virtuosa personal y reflexión política sobre el bien comunitario no reconoce un campo con especificidad y lenguaje propio: la filosofía del derecho. La ley como ordenamiento de razón se orienta por el principio natural de hacer el bien y evitar el mal, y al mismo tiempo distingue lo descriptivo del momento normativo. La engarza así en la tradición monoteísta, porque aunque creada por Dios, pertenece a la razón (no es divina), y aunque legible en el mundo, separa las acciones debidas a leyes de la naturaleza de las acciones orientadas por esas leyes. Tomás genera un concepto jurídico de ley, que distingue la base universal natural de las positivaciones jurídicas en su variación. Y genera de ese modo un modelo deontológico para la doctrina jurídica, relevante para la modernidad. ${ }^{78}$

Finalmente, el derecho racional moderno significó una transformación y una profundización de este curso. "La filosofía práctica reacciona ante las revoluciones protestantes y la progresiva secularización del poder estatal configurando el derecho racional". ${ }^{79}$ Tanto la reforma como la contrarreforma, y el humanismo, generan las condiciones de una racionalización del derecho, que toma antiguas nociones y seculariza sus bases. Un ejemplo notable es Suárez, que distingue ius y lex en el sentido de ley y derecho subjetivo en sentido moderno, dejando de lado el vínculo tomista con la ontología metafísica, e introduciendo así en el estado natural y su derecho el fundamento de los derechos subjetivos. ${ }^{80}$

75 Habermas, Auch eine Geschichte der Philosophie, 1, 661.

76 Habermas, Auch eine Geschichte der Philosophie, 1, 654.

77 Habermas, Auch eine Geschichte der Philosophie, 1, 665.

78 Habermas, Auch eine Geschichte der Philosophie, 1, 757.

79 Habermas, Auch eine Geschichte der Philosophie, 2, 14.

80 Habermas, Auch eine Geschichte der Philosophie, 2, 88. 
El paradigma de las ciencias naturales modernas conduce a diversos pensadores a intentar un modelo análogo para la filosofía práctica. Aparecen modelos nacidos de diversas interpretaciones del estado de naturaleza. Aunque todavía dependientes de una comprensión metafísica previa, son capaces de instaurar tres elementos provenientes de una comprensión renovada del derecho natural que dará pie al racional: su característica igualitaria, su comprensión constitucional en cuanto a la juridización del poder, y su elemento libertario por el paso del énfasis en las obligaciones al énfasis en los derechos. ${ }^{81}$ La creciente sociedad burguesa pone énfasis en los derechos subjetivos, que asumen un rol central para los teóricos del derecho racional. Se impone la perspectiva en primera persona del sujeto que reflexiona sobre conocimiento y acciones, frente a la totalización de las ciencias, que según Habermas desvaloriza la razón práctica. ${ }^{82}$

La filosofía del sujeto tiene sus efectos en el problema de la fundamentación de las normas. Las guerras de religión exigen otro tipo de configuración, por el cual el derecho racional secular pueda sobreponerse al déficit de integración. En las posiciones surgidas en esa época, que buscan en cierto estado de naturaleza las bases racionales de las normas vinculantes, no sólo se advierten criterios de derechos y garantías, sino además "el reconocimiento mutuo de las reflexiones individuales y la aceptación pública de un acto, al cual todos los partícipes se comprometen" ${ }^{33}$ En un momento de progresivo reconocimiento del pluralismo de opiniones y de la necesidad de un sistema jurídico que lo refleje y al mismo tiempo evite sus consecuencias destructivas, diferentes respuestas prevén el ingreso del criterio de mayoría y la unificación por parte del poder estatal, como criterios de justificación racional.

Kant y Hume reconocen las inconsistencias del derecho racional del siglo XVI, todavía atado a premisas metafísicas o religiosas, que desde la alta escolástica se expresaba en términos de derechos subjetivos. ${ }^{84}$ Hume parte de una antropología de los sentimientos individuales y piensa desde allí la posibilidad de consentir al orden universal del derecho (no fundado ni en justificaciones teológicas ni racionales), lo cual conlleva una contradicción. ${ }^{85}$ Por su parte, Kant reconstruye a partir de una filosofía trascendental un modelo de moral y de derecho todavía cognitivo, donde la razón misma es legisladora a partir de criterios que la constituyen. A pesar de su perspectiva trascendental, a partir del criterio de universalidad Kant provee un paso que será decisivo para el derecho racional postmetafísico: "La fundamentación del principio moral en Kant se alimenta, mutatis mutandis, de la intuición del derecho racional - ligada por Rousseau a la condición de construcción de la voluntad democrática - de que las leyes generales son racionales cuando su validez positiva se debe a la aprobación fundante de parte de todos aquellos posiblemente afectados" ${ }^{86}$ Buscan para la filosofía práctica una premisa postmetafísica, pero en ellos la respuesta implica, respectivamente, remitir a una fundamentación trascendental o sostenerse en el escepticismo, algo problemático para una posición que sea tanto postmetafísica como afín a la progresión igualitaria y fundamentada del derecho. ${ }^{87}$

81 Habermas, Auch eine Geschichte der Philosophie, 2, 102.

82 Habermas, Auch eine Geschichte der Philosophie, 2, 123.

83 Habermas, Auch eine Geschichte der Philosophie, 2, 147.

84 Habermas, Auch eine Geschichte der Philosophie, 2, 60.

85 Habermas, Auch eine Geschichte der Philosophie, 2, 288.

86 Habermas, Auch eine Geschichte der Philosophie, 2, 347.

87 Habermas, Auch eine Geschichte der Philosophie, 2, 562. 
En la historia del derecho racional moderno, entonces, hizo falta romper, primero, las ataduras de la filosofía al paradigma monodimensional de las ciencias naturales modernas, para mostrar que hay otra dimensión cognitiva y capaz de legitimar sus afirmaciones; y segundo, la perspectiva del sujeto trascendental. El derecho racional, comenzado desde el renacimiento y hasta Kant, toma en primera instancia como fundamentación la noción de derechos universales del ser humano, pero luego del historicismo del s. XIX esa fundamentación perdió su fuerza. Por eso, Habermas halla la fundamentación del derecho racional de modo pragmático y performativo, subordinando las fundamentaciones desde los Derechos Humanos y desde la soberanía popular al proceso constituyente de sujetos asociados, libres e iguales, coordinados por un procedimiento de legitimación. ${ }^{88}$. Habermas encuentra en el proceso y resultado de los estados constitucionales el núcleo donde política, moral y derecho postmetafísico exponen su procedimiento legitimatorio, heredero pero superador de los antiguos compromisos metafísicos, y en condiciones de mostrar un aprendizaje en las cuestiones de legitimación práctica.

\section{Conclusión}

El doble eje seleccionado muestra cómo Habermas elabora una síntesis que vincula procesos cognitivos y avance práctico a partir de la relación histórica de fe y conocimiento. En los tres ámbitos de legitimación práctica, política, moral y derecho, se da un avance hacia el pensamiento postmetafísico mediante el paso de una perspectiva contemplativa en tercera persona, a la objetivante moderna desde la primera persona, para llegar al momento actual de asumir la perspectiva del copartícipe del diálogo y universalizar el resultado de modo performativo. Todo esto permite, según Habermas, una respuesta no-derrotista a las crisis y desafíos, que afirma avances cognitivos e institucionales ya no a la luz de una doctrina metafísica o un sujeto trascendental, sino por la progresiva institucionalización de las demandas nacidas de sujetos libres, iguales y comunicativos. La herencia religiosa no se ve sólo en ese proceso, como se mostró anteriormente, sino también en la sensibilidad ante el sufrimiento y lo injusto, la experiencia de una obligación incondicionada, la intuición de una vida no-fallida, y una sensibilidad frente a las formas fallidas de vida común, elementos de procedencia religiosa pero que pueden sostenerse sin ella.

El impulso cognitivo que nace en la era axial está impulsado por las disonancias entre el saber profano y las explicaciones mitológicas. La sucesiva elaboración de imágenes del mundo religiosas y explicaciones metafísicas abarca las diversas funciones cognitivas de dar sentido a sí y al mundo, y de estabilizar las identidades y las sociedades. Esto genera una especie de intercambio directo entre ellas, y también un conflicto con las imágenes alternativas, que se radicaliza en la modernidad y el pensamiento postmetafísico. En el mundo empírico encontramos la resistencia de los hechos cuando las afirmaciones son falsadas, pero en el campo de las normas que buscan resolver conflictos lo que encontramos son oposiciones de otras personas que no encuentran representados sus intereses. "Aquí ingresa en lugar de la objetividad de los objetos de experiencia la intersubjetividad dañada de la socialización de personas que insisten en el reconocimiento de sus demandas negadas" ${ }^{89}$ En ese momento, sólo adoptando la posición del otro se permite reemplazar la "objetividad" de las cosas del mundo y asumir un interés generalizable.

88 Habermas, Auch eine Geschichte der Philosophie, 2, 762.

89 Habermas, Auch eine Geschichte der Philosophie, 2, 790. 
Es valiosa la diferenciación de pretensiones de validez y el requisito de traducir y lingüistificar lo religioso, so pena de atravesar el mundo de contenidos epistemológica y pragmáticamente insostenibles. Pero subsiste la pregunta de si esta "normalización" o "modernización" de la experiencia religiosa no corre el riesgo de eliminar el motor intraducible del misterio. No sólo aquel aspecto pragmático de solidaridad, que se expresa performativamente en el rito, sino también la "interrupción” (Metz) que es básica para lo religioso, que permite ver el mundo en otra perspectiva y que (a veces) expone demandas no reconocidas por los procedimientos instituidos. Y hay que sumar la pregunta - posiblemente no filosófica sino psicoanalítica - por el "nudo" con que cada sujeto ata en su singularidad esas diversas esferas y su capacidad de darles sentido, algo que muchas veces parece fuera del juego de las razones universalizables.

\section{Bibliografía}

Borradori, Giovanna,Jürgen Habermas y Jacques Derrida. Philosophy in a Time of Terror. Chicago: Unviersity of Chicago Press, 2003.

Calhoun, Craig, Eduardo Mendieta y Jonathan VanAntwerpen. Habermas and Religion. Cambridge: Polity Press, 2013.

Casanova, José. Genealogías de la secularización. Barcelona: Anthropos y Universidad Nacional Autónoma de México, 2012.

Conill, Jesús. “Teoría de la acción comunicativa como filosofía de la religión”. Estudios filosóficos, no. 128 (1996): 55-73.

Conill, Jesús. “Ética y religión”. Erasmus. Revista para el diálogo intercultural, no. 20 (2020): 91-108.

Estrada, Juan Antonio. Por una ética sin teología. Habermas como filósofo de la religión. Madrid: Trotta, 2004.

Habermas, Jürgen. Pensamiento postmetafísico. Madrid: Taurus, 1990.

Habermas, Jürgen. Facticidad y validez. Madrid: Trotta: 1998.

Habermas, Jürgen. Teoría de la acción comunicativa, Tomo 1. Madrid: Taurus 1999.

Habermas, Jürgen. Teoría de la acción comunicativa, Tomo 2. Madrid: Taurus 1999.

Habermas, Jürgen. Israel o Atenas. Madrid: Trotta, 2001.

Habermas, Jürgen. El futuro de la naturaleza humana. Barcelona: Paidós, 2002.

Habermas, Jürgen. Entre naturalismo y religión. Madrid: Trotta, 2006.

Habermas, Jürgen, y Josef Ratzinger. Entre razón y religión. México, FCE, 2008.

Habermas, Jürgen. Auch eine Geschichte der Philosophie, Tomo 1. Suhrkamp, 2019.

Habermas, Jürgen. Auch eine Geschichte der Philosophie, Tomo 2. Berlin: Suhrkamp, 2019.

Mardones, José María. El discurso religioso de la modernidad. Habermas y la religión. Barcelona: Anthropos/ Universidad Iberoamericana, 1998.

Ortega-Estembre, César y Marina Gracía-Granero. "La tesis de la postsecularización a la luz de la trayectoria intelectual de Jürgen Habermas". Cuadernos Salmantinos de Filosofía, no. 46 (2019): 71-97.

Schmidt, Thomas, y Annette Pitschmann. Religion und Säkularisierung: Ein interdisziplinäres Handbuch. Stuttgart: Metzler, 2014. 